\title{
O USO DA EXPRESSÃO “MAL-DE-SETE-DIAS” POR MÃES DE CRIANÇAS QUE MORRERAM DE TÉTANO NEONATAL EM MINAS GERAIS (1997-2002) ${ }^{1}$ USE OF THE EXPRESSION "SEVEN-DAY DISEASE” BY MOTHERS OF CHILDREN WHO DIED OF NEONATAL TETANUS IN MINAS GERAIS (1997-2002) \\ EL USO DE LA EXPRESIÓN “MAL DE LOS SIETE DIAS” POR LAS MADRES DE LOS NIÑOS QUE MURIERON DE TÉTANOS NEONATAL EN MINAS GERAIS (1997-2002)
}

\author{
Lúcio José Vieira ${ }^{2}$, Maria Helena Pessini de Oliveira ${ }^{3}$, Fernando Lefêre ${ }^{4}$
}

\begin{abstract}
'Desmembramento da tese "Reconstruindo a trajetória de mães de crianças que morreram por tétano neonatal em Minas Gerais", defendida em 27/04/2005 junto à Escola de Enfermagem de Ribeirão Preto (EERP), da Universidade de São Paulo (USP), com apoio financeiro da Fundação de Amparo à Pesquisa do Estado de São Paulo (FAPESP).

2 Enfermeiro. Doutor pelo Programa de Pós-Graduação em Enfermagem de Saúde Pública da EERP/USP. Professor Adjunto da Escola de Enfermagem da Universidade Federal de Minas Gerais (EEUFMG).

${ }^{3}$ Orientadora. Doutora em Enfermagem. Professora Livre Docente da EERP/USP.

${ }^{4}$ Sanitarista. Doutor em Saúde Pública. Professor Livre Docente da Faculdade de Saúde Pública da USP.
\end{abstract}

PALAVRAS-CHAVE: Vacinação. Cuidado pré-natal. Tétano. Recém-nascido. Fatores de risco.

KEYWORDS: Vaccination. Prenatal care. Tetanus. Newborn infant. Risk factors.

PALABRAS CLAVE: Vacunación. Atención prenatal. Tétano. Recién nacido. Factores de riesgo.

RESUMO: Neste artigo buscou-se compreender, por meio do discurso de 19 mães de crianças que morreram de tétano neonatal no Estado de Minas Gerais, as representações sobre os meios de prevenção da doença, destacando-se o modo como foi cuidado o coto umbilical. Dados secundários, obtidos no Cartão da Gestante e nas Fichas de Notificação, foram utilizados para melhor compreensão das falas das entrevistadas. A metodologia adotada foi de natureza quantitativa e qualitativa com enfoque nas representações sociais sobre a experiência da doença. Para a análise das entrevistas foi utilizado o instrumento "discurso do sujeito coletivo". Observou-se a presença da crendice sobre os cuidados com o coto umbilical e a falha dos serviços no processo de educação para a saúde. Urge programar esforços estratégicos direcionados à capacitação de parteiras e profissionais de saúde, incrementar serviços de pré-natal e ampliar a cobertura vacinal, principalmente nas regiões de onde provêm os casos da pesquisa, contribuindo para a eliminação da doença.

ABSTRACT: This study aimed to understand the representations on the means of preventing neonatal tetanus, based on the discourse of 19 mothers of children who died of this disease in the State of Minas Gerais, Brazil, highlighting care for the umbilical cord stump. Secondary data, taken from the Pregnant Woman's Card and the Notification Cards, were used to acquire a better understanding of the interviewees' discourse. A quantitative and qualitative methodology was adopted, focusing on the social representations about the disease experience. The interviews were analyzed on the basis of the "collective subject discourse" instrument. The mothers' discourse revealed the presence of popular beliefs in care related to the umbilical cord stump and the services' deficiencies in the health education process. There is an urgent need to program strategic efforts aimed at the training of midwives and health professionals, as well as to increase prenatal services and expand vaccination coverage, mainly in the research cases' regions of origin, thus contributing to the elimination of this disease.

RESUMEN: La finalidad de este artículo fue comprender, através del discurso de 19 madres de niños que murieron a consecuencia del tétanos neonatal en el Estado de Minas Gerais, Brasil, las representaciones sobre los medios de prevención de la enfermedad, destacándose la manera como fue cuidado el cordón umbilical. Datos secundarios, obtenidos en la Tarjeta de la Mujer Embarazada y en las Tarjetas de Notificación, fueron utilizados con miras a una mejor comprensión de los discursos de las entrevistadas. La metodología adoptada fue de naturaleza cuali-cuantitativa con enfoque en las representaciones sociales sobre la experiencia de la enfermedad. Para el análisis de las entrevistas fue utilizado el instrumento "discurso del sujeto colectivo". Se observó la presencia de la creencia popular sobre los cuidados con el cordón umbilical y la deficiencia de los servicios en el proceso de la educación para la salud. Es urgente programar esfuerzos estratégicos específicos, dirigidos hacia la capacitación de parteras y profesionales de la salud, incrementar servicios de prenatal y ampliar la cobertura de vacunación, principalmente, en las regiones de donde provienen los casos de la investigación, contribuyendo asi para la eliminación de la enfermedad.

Endereço: Lúcio José Vieira R. Turquesa, 905

30.480-040 - Belo Horizonte, MG.

E-mail:vieira@ufmg.br
Artigo original: Pesquisa

Recebido em: 10 de agosto de 2005

Aprovação final: 20 de fevereiro de 2006

Texto Contexto Enferm, Florianópolis, 2006; 15(1): 51-9. 


\section{INTRODUÇÃO}

O tétano neonatal se mantém como um importante problema de saúde pública na maioria dos países subdesenvolvidos, sendo a doença em muitos países das Américas, responsável pela metade das mortes neonatais e por $25 \%$ da mortalidade infantil. ${ }^{1-3}$

A ocorrência da doença está intimamente relacionada com as condições socioeconômicas, pois altas incidências são encontradas nas camadas pobres da população que não possuem acesso aos serviços obstétricos e pré-natais e, sobretudo, entre as crianças nascidas de partos domiciliares realizados por parteiras e curiosas. $^{4,5}$

Em pleno século XXI, depois da erradicação da varíola, da poliomielite, do controle do sarampo e de outras doenças imunopreveníveis, é uma contradição ainda deparar com a ocorrência de tétano neonatal no Brasil.

A extensão da cobertura vacinal contra o tétano neonatal nem sempre consegue atingir todas as gestantes e mulheres na idade fértil, seja por ineficácia dos serviços, seja por descaso das pessoas que privilegiam as crianças esquecendo-se de si mesmas.

No Brasil, embora se observe uma tendência ao declínio da taxa de incidência do tétano neonatal a partir de 1983, ainda é necessário implementar e intensificar as ações de controle preconizadas pela Organização Mundial de Saúde (OMS), pois essas taxas ainda são preocupantes, em decorrência da alta letalidade da doença, que se situa entre $50 \%$ a $80 \%{ }^{3}$

Em Minas Gerais, observamos a diminuição da taxa de incidência por tétano neonatal ao longo dos anos, mas mesmo assim continua com uma freqüência acima da encontrada para o País. Em 1998, a taxa de incidência no Estado foi de 1.85 por 100 mil habitantes, enquanto para o mesmo ano, no País, foi registrada a taxa de 0.4 para 100 mil habitantes. ${ }^{6,7}$

O estudo realizado em Minas Gerais, ${ }^{8}$ mediante um levantamento de dados secundários, revelou a presença do tétano neonatal tanto em áreas rurais como urbanas, com predomínio de casos de procedência rural $(59,4 \%)$. Dos 70 casos estudados, ficou evidente o predomínio de óbitos em municípios das Regiões Norte, Nordeste e do Vale Jequitinhonha do Estado de Minas Gerais (63,5\%), localizados nas áreas pobres e desprovidas de recursos. A maioria dos partos $(65,3 \%)$ ocorreu no domicílio e 60,8\% foram assistidos por pessoa sem qualificação profissional, predominando as parteiras tradicionais, constando que 75,4\% das mães não freqüentaram o pré-natal.
Este artigo apresenta os achados de entrevistas realizadas com mães de crianças que morreram de tétano neonatal em Minas Gerais de 1997 a 2002, no que diz respeito às representações da expressão "malde-sete-dias" e sua correlação ou não com a doença.

Representações sociais podem ser compreendidas como um conjunto de conceitos, proposições e explicações originadas na vida cotidiana no curso das comunicações interpessoais. As representações sociais são o equivalente, em nossa sociedade, aos mitos e sistemas de crenças das sociedades tradicionais, podem também ser vistas como a versão contemporânea do senso comum. ${ }^{?}$

Acreditamos que indagar a respeito da realidade das mães com as suas representações sociais sobre o adoecer dos seus filhos pelo tétano neonatal permite compreender melhor esse problema e trazer contribuições para o controle da doença.

\section{METODOLOGIA}

Realizamos um estudo quantitativo e qualitativo, no qual o dado numérico foi extraído das Fichas de Notificação e Cartões das Gestantes, contribuindo com elementos importantes para a visualização do cenário da pesquisa e a melhor compreensão das falas das mães.

Acreditamos que "[...] incluindo os dados operacionalizáveis e junto com o conhecimento técnico, qualquer ação de tratamento, e prevenção ou de planejamento deveria estar atenta aos valores, atitudes e crenças dos grupos a quem a ação se dirige. É preciso entender que, ao ampliar suas bases conceituais, as ciências sociais da saúde não se tornam menos científicas, pelo contrário, elas se aproximam com maior luminosidade dos contornos reais dos fenômenos que abarcam". 10:16

Os métodos quantitativo e qualitativo de pesquisa são diferentes, porém não são excludentes porque, na verdade, colocam-se questões diversas baseadas em construções teórico-metodológicas com princípios diferenciados. Portanto, é possível trabalhar de forma complementar com as duas metodologias, no sentido de que o resultado de uma questão, colocada a partir de princípios teórico-metodológicos quantitativos, suscite novas questões que só possam ser avaliadas sob princípios qualitativos, ou vice-versa. ${ }^{11}$

A pesquisa foi realizada em municípios das Diretorias de Ações Descentralizadas de Saúde de Minas Gerais, área onde se encontram 60\% dos casos notificados de tétano-neonatal da Região Sudeste. 
Para o período 1997-2002, dispúnhamos de 26 casos notificados de crianças que evoluíram para óbito por tétano neonatal. Foram entrevistadas 19 mães, pois 6 não foram localizadas em decorrência do paradeiro ignorado, e 1 criança não havia evoluído para óbito, ao contrário do que constava na Ficha de Notificação, e estava completando 5 anos por ocasião da entrevista. Essa constatação reforça o estudo por meio do qual se pode observar quão precário é o preenchimento das Fichas de Notificação, apontando a necessidade de treinamento dos profissionais para essa atividade tão importante da vigilância epidemiológica. ${ }^{8}$

O estudo foi autorizado pelo Comitê de Ética e todos os participantes subscreveram o Termo de Consentimento Informado.

A coleta de informações foi feita mediante entrevista semi-estruturada, realizada individualmente, constando de cinco questões abertas norteadoras sobre o assunto e respeitando a livre expressão de suas representações. ${ }^{12}$ As entrevistas foram gravadas com a aquiescência das entrevistadas.

Antes de começar a transcrição, as entrevistas foram ouvidas várias vezes, visando à compreensão das falas, em seguida fez-se o registro literal de todos os depoimentos orais. Cada uma das entrevistas recebeu um código (E), ficando assim denominadas: $\mathrm{E} 1=$ entrevista 1, E2 = entrevista 2, e assim sucessivamente, até E19 = entrevista 19.

Utilizou-se para a organização dos dados a proposta metodológica do Discurso do Sujeito Coletivo (DSC), uma nova abordagem na pesquisa qualitativa. ${ }^{13}$

Esses autores afirmam que, qualquer que seja a técnica utilizada pelo investigador, os depoimentos são discursos, os quais, uma vez que se trata de pesquisa qualitativa, devem permanecer inalterados. Processar depoimentos significa agrupar ou agregar elementos em conjuntos, ou seja, somar qualidades, qualitativamente. Portanto, a soma de discursos individuais dá como resultado um ou vários discursos do sujeito coletivo. Acrescenta-se, ainda, que o pensamento coletivo não está ligado ao somatório dos pensamentos individuais, portanto, há uma representação numérica percentual, relacionada ao discurso da coletividade, ao imaginário social, às representações sociais, ao pensamento preexistente.

O Discurso do Sujeito Coletivo visa fazer as correlações que a coletividade traz nos seus discursos além de carregar os valores intrínsecos, próprios da cultura que está no cotidiano dos sujeitos sociais.
Parte-se dos discursos em estado bruto, que são submetidos a um trabalho analítico inicial de decomposição que consiste, basicamente, na seleção das principais idéias centrais presentes em cada um dos discursos individuais e em todos eles reunidos, e que termina de forma sintética, onde se busca a reconstituição discursiva da representação social. ${ }^{13}$

\section{RESULTADOS}

As informações registradas por meio dos dados secundários foram fundamentais para melhor compreensão das falas das entrevistadas.

Provavelmente em razão da baixa escolaridade, as mães tiveram dificuldades no fornecimento dos dados referentes ao número de consultas de pré-natal, doses de vacina e mesmo em relação à própria idade. Das 19 mães entrevistadas, 6 não tinham nenhuma escolaridade, 11 estudaram de 1 a 4 anos e 2 estudaram de 5 a 8 anos. Na zona rural residem 14 mães e na zona urbana, 5 .

Com relação à formação escolar, podemos afirmar que o nível de escolaridade das mães é muito baixo, realidade que condiz com o contexto em que vivem, representado por uma qualidade de vida rural subdesenvolvida, na qual predominam precários níveis socioeconômicos.

Quanto à gravidez, apenas uma mãe era primípara, tendo como referência a época do nascimento da criança que morreu por tétano neonatal (TNN), sendo as demais mães multíparas, com uma média atual de 4,8 filhos vivos.

Em estudo sobre nascidos vivos que não tiveram assistência pré-natal, ou cujo parto foi realizado no domicílio, segundo o nível de escolaridade da mãe, verificou-se que, para mulheres sem escolaridade, os percentuais alcançados nessas duas variáveis são próximos a $45 \%$ e $25 \%$, respectivamente, ao passo que, para mulheres com mais de 12 anos de estudo, o percentual cai para zero nas duas variáveis. ${ }^{14}$

Quanto à ocupação, 11 mães exerciam atividades do lar, além de cuidar de pequenos animais e da agricultura de subsistência, sendo o excedente da produção trocado por outras mercadorias para a sobrevivência da família. Uma das mães, além de ser do lar, exerce também a atividade de catadora de papel. As outras 7 mães, além de serem do lar, trabalhavam como diarista, sendo seis trabalhadoras rurais, principalmente no plantio e na colheita da cana-de-açúcar, do feijão e do café e uma como ajudante de carvoaria. 
Apenas 2 mães possuíam o Cartão da Gestante relativo ao pré-natal da criança que morreu por tétano neonatal, sendo que em ambos só constava o registro de uma consulta entre o sexto e o oitavo mês. Uma das mães afirmou ter queimado o Cartão da Gestante junto com todos os documentos da criança por ocasião do óbito e que consultou apenas uma vez.

Em estudo realizado pelo Ministério da Saúde sobre os 64 casos de tétano neonatal ocorridos no País em 2001 e 2002, com referência ao número de consultas de pré-natal das mães das crianças, verificou-se que 49 mulheres não realizaram nenhuma consulta, 2 mulheres realizaram uma consulta, 5 realizaram duas consultas, 1 realizou três consultas e somente 6 referiram 4 consultas e mais. ${ }^{15}$

Pela situação vacinal das mulheres entrevistadas no momento da ocorrência do caso de tétano neonatal comprovou-se que 11 mães não haviam tomado nenhuma dose da vacina Dupla Adulto e 3 tomaram apenas uma dose, portanto insuficiente para proteger o recém nascido contra o tétano neonatal. Duas mães tomaram duas doses de vacina Dupla Adulto e três que tomaram três doses, neste caso levando a hipótese da possibilidade de problema com relação a cadeia de frio, quanto à validade das vacinas, ou quanto a técnica de aplicação da vacina, situações que podem comprometer o processo de imunidade não conferindo proteção ao recém nascido.

Foram listadas, em um único instrumento de análise de discurso (IAD2), todas as idéias centrais e todas as expressões-chave para cada um dos sujeitos, relativas às mesmas respostas para cada uma das cinco perguntas da entrevista, com total resgate da literalidade dos sujeitos em questão. A localização das expressõeschave demandou várias releituras das entrevistas, tendo em vista que, em muitas ocasiões, pensamentos que respondiam determinadas questões estavam em outras falas das mães. O passo seguinte foi reunir em torno de uma ou mais "idéias centrais" esses pensamentos expressos, buscando sempre preservar a fidelidade deles.

Para este artigo apresentaremos apenas a análise relativa à questão referente ao conhecimento da expressão "mal-de-sete-dias".

\section{DESENVOLVIMENTO DO INSTRUMENTO DE ANÁLISE DE DISCURSO - 2 (IAD-2)}

\section{A senhora sabe o que é “mal-de-sete-dias"?}

\section{Idéia central}

Eu já ouvi falar de mal-de-sete-dias. O povo diz que quando ocorre o mal-de-sete-dias, eles morrem. Eu não fiquei sabendo se meu filho morreu foi de malde-sete-dias.

\section{Expressões-chave}

E.1 Não. É, eu já vi falar. Eu sei assim, que o povo fala que quando dá o mal-de-sete-dia que eles morre, né? Eles vão chorando, chorando, até que morre, com o mal-de-sete-dia [...]. Eu não fiquei sabendo se foi o mal-de-sete-dia, pois ele morren e en vim embora. Eu não fiquei sabendo. Ele foi sepultado no Planalto aqui. Foi a primeira vez. que morre uma criança aqui. Depois dele eu ainda não quis ter mais filho não. Antes dele foi seis filhos, com ele sete.

E.2 Num sei não. Eles fala que é teto que deu no imbigo do menino, né?

E.3 Minha mãe só, sempre falava comigo desse negócio de [...] que menino morria com sete dia, com mal-de-sete-dia. Só que dir que morre com mal é assim que faz sete dia. Só que ela morreu tava com dois mês. Oh, diz a minha mãe que era uma irmã dela é que teve. [...] Só que eu mesmo num sei direito não. Eu já ouvi falá disso. Só que eu num tenho conhecimento disso não. Eu só vi falá pra lá só, mas eu nunca prestei atenção direito não. Agora que ouvi falá nas coisa de doença assim, eu presto mais atenção poquê a gente que tem menino [...] Eu presto mais atenção mais nas coisas pra sabê de reação de menino, pra sabê do jeito que é pra gente sabê cuidá. 
Eu já ouvi falar de tétano. Eles disseram que é muito no umbigo para não dar tétano. perigoso e que a gente tem de usar álcool absoluto

E.4 Num sei. Této também num sei. Já ouvi falá. Eles falaram que a gente tem que usá álcool absoluto poquê senão vai této no imbigo. E é muito perigoso. Foi isso que falaram comigo.

Eu não sei muito bem, mas o mal-de-sete-dias faz com que a cabeça deles seja rachada. Então, eles não raciocinam nada.

Eles falaram que ela morreu foi de mal. Eles só escreveram que foi com mal.

Eu ouvi falar de mal-de-sete-dias e de tétano, mas não sei o que significa.

Eu ouvi falar de mal-de-sete-dias e de tétano, mas não entendo. Alguém mais velho me disse que antigamente se morria de mal-de-sete-dias.

Eu acho que o médico falou que ele morreu foi de mal de umbigo. Eu não sei e não ouvi falar de tétano.

Eu já ouvi falar de mal-de-sete-dias. Muitas pessoas disseram que não adiantava levar meu filho para o hospital. Mas eu levei para ver se ele melhorava.

Eu não conheço direito, mas o povo diz que, quando dá o mal-de-sete-dias, eles morrem com os ossinhos da cabeça quebrados. Mas o médico falou que foi por falta de cuidado com o umbigo dele. Eu já ouvi falar de tétano, mas também não conheço direito.

Sobre mal-de-sete-dias eu sei pouco. Lá em Teófilo Otôni eles disseram que ele teve foi mal de umbigo. Eu acho que mal de umbigo é a mesma coisa que tétano.
E.5 Eu num sei não. É mal-de-sete-dia por isso [...]. Poquê quando eles nasce num raciocina nada. A cabeça deles é rachada aqui assim, aqui assim. Esse aqui também tem.

E.6 Se eu sei? (silêncio) Eles falô que ela morreu foi de mal. Eles só colocava lá que foi de mal.

E.7 Já ouvi falá. Eles fala mal-de-sete-dias, né? Eu num sei não. Tétalo também não. Eu vejo falá, mas num sei o que significa. Eu só vi o médico falá, né?

E.8 [...] eu num gravei na cabeça não. Sei não. É poquê tem tempo isso, né? Tá com quatro anos, cinco anos, talvez se fosse mais de novo eu inté lembrasse. Eu não sei não. Eu já esqueci. Eu não. Num intendo. Num sei o quê que é isso não. Nem isso. Num sei também não. Essa coisa, esse aí. Ab, esse aí eu acho que [...] Alguma pessoa falô pra mim. Essas pessoa de mais idade, né? Falô comigo. Antigamente morria de mal-de-sete-dia. Agora eu num sei de que é isso. Se é mal-de-sete-dia, num sei o que quê é? Se é teto, num sei o que quê é? É só mais essas pessoa sabida que tira do, as vezes acha assim na medicina, né? É que sabe.

E.9 Eu num sei não. Ele faleceu foi no hospital. O médico, eu acho que falô que ele deu foi o mal de umbigo. Mal de umbigo que deu nele. Eu num sei não. Eu num ouvi falá de tétano não.

E.10 Já. Mal-de-sete-dias já vi. Que muitas disse que quando tem mal, que num tinha que levá. Poquê que era o mal-de-sete-dias, né? De lá pra cá, disse que muitas crianças morria assim, né? De malde-sete-dias. Ai eles disse que eи num tinha que levá, mas en levei pra ver se ele sarava. Pra Deus dá ele saúde. Eu levei, né? Que ia levá pra ver se ele melhorava. Mas muita pessoa falava que eu num tinha que levá não, poquê era essa doença mal-de-sete-dias.

E.11 Ah, o povo me conta, né? Eu num conheço direito não. Mas, o povo me fala que o mal-de-sete-dias é assim quando eles morre que quebra o ossinho da cabeca toda. Que estoura os ossinho toda assim e rouxeia as unhas, a boca. Foi isso que eles me falô, que é o mal-desete-dias é assim. Eu num sei, que um cado do povo da família dele falô que era o mal-de-sete-dias, né? Mas o médico falô que foi falta de cuidado com o umbigo dele. Eu num sei. Tétano eu num conbeço direito essa doença não. Eu já ouvi falá. Tétano. Eu num sei que doença é não.

E.12 Se eu sei? Mal-de-sete-dias eu não sei muito não. Ele sentiu foi mal, né? Foi uma cólica brava. Que num teve jeito não, né? Lá em Teófilo Otôni eles diz que é mal de umbigo. Essa doença aí eu num sei como é que ela chama não. Essa doença é mesmo que mal de umbigo mesmo, né? Tetro é mal de umbigo mesmo. 
Eles falam que o menino adoece. É um mal que dá, chamado mal-de-sete-dias.

Eu esqueci o que é mal-de-sete-dias. As vacinas são para evitar o mal-de-sete-dias na criança.

Já ouvi falar de mal-de-sete-dias. Eu acho que tétano é uma coisa e mal-de-sete-dias é outra coisa. Eu fui saber o que é tétano depois que minha filha tinha falecido.
E.13 Eles fala assim, que o menino doece. Que é um mal que dá. $O$ mal-de-sete-dias.

E.14 Eu não, eu esqueci. O menino de men cunhado aqui, esse que caminha patinando. Foi mal-de-sete-dias. As vacinas é pra isso aí, né? Pra não dá o mal no menino, né? Na criança [...]. O doutor Joaquim mesmo, aí, no hospital em Maxacalis, falou pra mim que podia trazêe o menino pra casa poquê o menino num tinha jeito mais, né? Porque era mal-de-sete-dias que era.

E.15 Eu já ouvi falá de tétro. Foi depois do que aconteceu com a minha menina. Depois disso ai é que foi que eu fui sabe, aliás, depois disso ai a menina tinha, tinha falecido, com 10 dias, com 10 dias, com 14 dias en operei. Eu tava de resguardo, fraca, sentida, depois eu operei. Operei em Divisópolis, não operei em Conquista. Apesar de que, depois dessa operação en fiquei com muitos, com muitos problema, sabe? Com muitos problema. Já ouvi falá de malde-sete-dias. Eu não sei. Eu acho que tetro é uma coisa e mal-desete-dias é outro.

E.16 Mal-de-sete-dias que não pode tomá vento, né? Não pode tomá resfriado, né? O que eu sei é isso. Não deixa tomá, né? Principalmente o vento frio, né? É isso que nóis faz aqui na roça. Minha filha não pode ter pegado o mal-de-sete-dias porque não panhou vento nenhum, né? Não teve resfriado nenhum, né? Eu acho que o mal que chegou ao conbecimento dela, porque eu acho que ela nasceu fraca, o líquido dela, né? Eu tava perdendo líquido, ela nasceu uma menina muito fraca e não suportou, né?

E.17 Já ouvi falar de mal-de-sete-dias, mas eu não sei não (risos) o que é não e nun... nunca vi não. Eu não sei o que é tétano também não. Eu sei que o теи assim adoeceu, serrou o queixinho, não conseguiu chorar, não mamava. Eu sei explicá do tétano é só até aí. rar e não mamava. É só isso que eu sei explicar sobre tétano.

O que eu sei do mal-de-sete-dias é que a criança não pode sair de casa. Deve ficar fechada no quarto e com a tesoura aberta na parede. Mas eu acho que tem um monte de bobagem. Minha filha teve foi tétano.

Eu já ouvi falar de mal-de-sete-dias. Eles dizem que não se pode sair de casa com a criança nem dar banho nela até completar os sete dias. Na minha filha banho eu dei, só não saí com ela de casa. Eu não sabia de tétano. Eu acho que mal-de-sete-dias é uma coisa e tétano é outra.
E.18 Sei. O mal-de-sete-dias é que o menino não pode sair pra fora, né? Fechado num quarto, tesoura aberta na parede. Não deixá toma ar, né? Pra bem dizer, eu acho que tem um monte de bobagem. [...] Ela cain o imbigo com 8 dias [...] com 8 dias deu poblema do tetro.

E.19 Eu já vi fala. Uai eles fala que num pode saí com a criança inté os sete dia. Num pode saí com a criança pra fora. Eles fala que num pode dá banho. Isso é o que eu intendo. [...] Nas minha eu dei, o banho eu dei. Eu só num saí com elas porquê eles fala que num pode vê a claridade do dia. Vê a claridade do dia eu num deixava eles vê mesmo não. Inclusive, de saí com a criança pra fora. Bem eu num lembro de tetro não. Somente eu num sabia. Chegô lá no Araxá eles colocô no papel. Uai, dir eles que somente se ficá sem tomá a vacina. Tomá a vacina, en tomei. Mal-de-sete-dias e tetro? Eu acho que uma coisa é outra, uma é outra. 
Das idéias centrais agrupadas em relação a conhecer o mal-de-sete-dias, resultantes das falas muito heterogêneas das mulheres que compõem o grupo, obtivemos os seguintes "discursos dos sujeitos coletivos": 1) eu já ouvi falar de mal-de-sete-dias, mas eu não tenho muito conhecimento. Só que dizem que a criança morre com mal assim que faz sete dias. Eles vão chorando, chorando até morrer com o mal-de-setedias. Eu não fiquei sabendo se meu filho morreu com mal-de-sete-dias; 2) eu já ouvi falar de mal-de-setedias. Minha mãe falava que menino morria com sete dias, com mal-de-sete-dias. Só que diz que morre com esse mal assim que faz sete dias. Eu não acredito que minha filha morreu com mal-de-sete-dias, pois ela morreu com mais de sete dias; 3) o que eu sei do malde-sete-dias é que o neném não pode tomar vento e nem resfriado. Minha filha não pode ter tido o mal-desete-dias porque não pegou vento, nem resfriado. Eu acho que o mal dela foi porque nasceu fraca; 4) eu não sei o que é mal-de-sete-dias. Eles falam que é tétano que deu no umbigo do meu filho. Eles falaram que é muito perigoso e que a gente tem de usar álcool absoluto no umbigo para não dar tétano. Acho que mal de umbigo é a mesma coisa que tétano, mas acho que tétano não é a mesma coisa que mal-de-sete-dias; 5) eles dizem que não se pode sair de casa com a criança nem dar banho nela até completar os sete dias. Deve ficar fechada no quarto, não pode ver a claridade e com a tesoura aberta na parede. Mas eu acho que tem um monte de bobagem. Eles colocaram no papel que minha filha teve foi tétano e disseram que ocorre se ficar sem tomar a vacina. Eu acho que mal-de-setedias é uma coisa e tétano é outra; 6) eu já ouvi falar de mal-de-sete-dias. Eles falam que o neném não pode sair de casa, nem se pode dar banho nele até completar os sete dias. Na minha filha eu dei banho, só não saí com ela para fora da casa. Eu não sabia de tétano. Só soube quando minha filha morreu; 7) eu não sei muito bem, mas o mal-de-sete-dias faz com que a cabeça deles seja rachada, de modo que eles não raciocinam nada. Quando morrem, estão com os ossinhos da cabeça quebrados; 8) eu esqueci o que é mal-de-sete-dias, mas o médico me disse que meu filho teve essa doença e que não sobreviveria. As vacinas são para evitar o malde-sete-dias na criança; 9) eu já ouvi falar de mal-desete-dias, mas não sei o que é. Eu não sei o que é tétano também. O meu filho adoeceu, travou o queixinho, não conseguia chorar e não mamava. É só isso que eu sei explicar sobre tétano.

A expressão mal-de-sete-dias ou simplesmente "mal" ou "male" ainda está presente em Minas Ge- rais, principalmente na zona rural. As mulheres atribuem a sua ocorrência ao fato de a criança até o sétimo dia ficar desprotegida do vento e da claridade. Em alguns casos, os contatos da mãe com a criança se limitam aos momentos da amamentação, preconizando-se até mesmo a necessidade de que ela também evite o contato com a parte externa da casa, procedimento preservado por comunidades que ainda acreditam ser importante o período determinado como resguardo. Resquardo é o ato da puérpera resquardar-se no período subseqüente ao parto, observando cuidados principalmente em relação ao repouso e a alimentação. ${ }^{15}$ Algumas mães correlacionam mal-de-sete-dias ao tétano umbilical, outras não fazem essa correlação, predominando aquelas que fazem a correlação, de modo que torna importante a utilização desta sinomínia nas ações educativas.

Nenhuma das mulheres fez menção à visita do agente comunitário de saúde ou outro profissional de saúde durante a gravidez ou período neonatal, para prestar orientações sobre amamentação, cuidados com o recém-nascido ou esclarecer dúvidas. É imprescindível o acompanhamento das puérperas mediante visita domiciliar, reforçando as orientações recebidas durante o pré-natal quanto aos cuidados com o coto umbilical.

Observamos a ausência de fala, por meio da qual fica implícito o recebimento de alguma orientação, individual ou em grupo, quanto aos cuidados a serem ministrados à criança no domicílio, ou que a mãe viesse a procurar ou receber a atenção dos profissionais da rede básica de saúde durante o puerpério.

Torna-se um desafio o desenvolvimento de atividades de educação para a saúde com pessoas, principalmente nas comunidades rurais, pois depende da disponibilidade de tempo das mulheres e homens envolvidos no trabalho, incluindo as atividades agrícolas.

Mesmo que o profissional de saúde tenha feito referência ao diagnóstico de tétano ou tétano umbilical, percebe-se que os sujeitos demonstram desconhecer a doença, embora para algumas tenha chegado a informação de que a causa do óbito foi o tétano. Algumas mães conseguem descrever os sinais ou sintomas relacionados com a doença, mesmo que não conheçam a sua terminologia correta, e outras relacionam a doença aos cuidados com o umbigo.

\section{CONCLUSÃO}

Por intermédio das entrevistas, há indícios de que o uso das expressões "tétano umbilical", "mal do 
umbigo" e "mal-de-sete-dias", sendo as duas últimas de uso popular, poderiam auxiliar na veiculação das medidas preventivas do tétano neonatal para que a população tivesse melhor clareza a que doença se refere. Por isso recomendamos à Coordenação de Doenças Imunizáveis da Secretaria de Estado da Saúde de Minas Gerais a utilização dessa terminologia no material educativo referente ao Plano de Eliminação do Tétano Neonatal.

De modo geral, as entrevistadas falaram a respeito de práticas populares bastante sedimentadas, relacionadas a cuidados para si e para os recém-nascidos, principalmente durante os primeiros sete dias, período que geralmente coincide com a queda do cordão umbilical, no sentido de evitar que a criança adoeça ou que a mãe possa provocar-lhe algum mal. Nesse sentido, parece haver um risco não calculado permeando tais atitudes: "O risco é inerente à condição do homem [...], a vida cotidiana multiplica as ocasiões de risco por falta de atenção, negligência, desconhecimento de lugar, ou imperícia dos outros". ${ }^{17: 7}$

Mesmo que a mulher tenha sido orientada sobre a forma correta de prestar esse cuidado, a influência do grupo social a que pertence é tão forte que paira dúvida entre as novas orientações e as antigas. Do outro lado, algumas mães têm receio de machucar a criança e delegam essa tarefa a outra pessoa, que nem sempre está preparada. O medo é uma característica do ser humano, um comportamento de conservação.

Faz-se necessário melhor preparo dos profissionais de saúde durante a sua formação e durante a sua atividade profissional no sentido de abordar os pacientes com atenção, de forma gentil e usando uma linguagem clara, simples e compreensível em todos os momentos do atendimento.

Fica evidente, mediante as representações encontradas, que conhecendo as idéias e crenças positivas e negativas sobre o tétano neonatal, torna-se possível maior compreensão das atitudes tomadas pelas gestantes e puérperas, as conseqüências que estas atitudes podem repercutir em relação ao recém-nato e, conseqüentemente, fornece subsídios para uma atuação mais direcionada, pois os profissionais buscam minimizar as representações que favorecem a existência da doença, sejam elas objetivas ou subjetivas, e fortalecer aquelas que podem favorecer a prevenção da doença.

É necessário buscar estratégias nos municípios para que todas as gestantes sejam cadastradas e acompanhadas durante o pré-natal e o puerpério, de modo a serem desenvolvidas ações previstas, entre elas a vacinação antitetânica e a visita domiciliar, para possibilitar o bom desenvolvimento da gravidez, do parto e o acompanhamento do recém-nascido.

\section{AGRADECIMENTOS}

Agradecemos à Coordenação de Aperfeiçoamento de Pessoal de Nível Superior (CAPES) pela bolsa de doutorado. Agradecemos à Fundação de Amparo a Pesquisa do Estado de São Paulo (FAPESP) pelo auxílio pesquisa para a realização da coleta de dados.

\section{REFERÊNCIAS}

1 Boletin Informativo del Programa Ampliado de Inmunizacion. La mortalidad por tétanos neonatal. OPAS 1991 Abr; 13 (2): 5-7.

2 Galazka A, Stroh G. Guidlines on the community: based survey on neonatal tetanus mortality. Geneva: OMS; 1986.

3 Ministério da Saúde (BR), Centro Nacional de Epidemiologia. Guia de Vigilância Epidemiológica. Brasília (DF): Fundação Nacional de Saúde; 1998.

4 Conyer RT, Amor JS, Izaba BS, Diaz AT, Carrilho LL, Muñoz JLC et al. Factores associados a la mortalidad por tétanos neonatal em el área rural de Jalisco. Salud Pública de México. 1991 Mai-Jun; 33(3): 207-13.

5 World Health Organization. Expanded Programme on Immunization. Weekly Epidemiological Record 1988 Jan; 63(3):9-16.

6 Secretaria de Estado da Saúde de Minas Gerais. Coordenadoria de Doenças Controláveis por Imunização Situação do tétano neonatal: relatório técnico. Belo Horizonte (MG): Secretaria de Estado da Saúde; 1999.

7 Lemos JAC, Rodrigues RCM. Plano de eliminação do tétano neonatal. Presente 2003 Set-Nov; 1(3):8-9.

8 Vieira LJ. Contribuição ao estudo epidemiológico do tétano neonatal no estado de Minas Gerais de 1989 a 1996: um enfoque de risco [dissertação]. Belo Horizonte (MG): Escola de Enfermagem da UFMG;1998.

9 Padilha MICS. Representações sociais: aspectos teóricometodológicos. 1a ed. Passo Fundo (RS): Universidade de Passo Fundo; 2001.

10 Minayo MCS. O desafio do conhecimento. Pesquisa qualitativa em saúde. 3a ed. São Paulo(SP): Hucitec;1994.

11 Victóra CG, Knauth DR, Hassen MNA. Pesquisa qualitativa em saúde: introdução ao tema. Porto Alegre (RS): Tomo Editorial; 2000.

12 Triviños ANS. Introdução à pesquisa em ciências sociais: a pesquisa qualitativa em educação. São Paulo(SP): Atlas; 1987. 
13 Lefèvre F, Lefèvre AMC, Teixeira JJV. O discurso do sujeito coletivo: uma abordagem metodológica em pesquisa qualitativa. Caxias do Sul(RS): EDUCS; 2000.

14 Medic AC. Uma década de SUS (1988-1998): progressos e desafios. In: Galvão L, Díaz J, organizadores. São Paulo(SP): Hucitec: Population Council; 1999. p.104-50

15 Ministério da Saúde (BR). Centro Nacional de Epidemiologia. Evolução do plano de eliminação do tétano neonatal no Brasil, situação atual e diretrizes para 2003. Brasília(DF): Fundação Nacional de Saúde; 2003.
16 Ferreira ABH. Novo Aurélio Século XXI: o dicionário da língua portuguesa.3a ed. Rio de Janeiro(RJ): Nova Fronteira;1999.

17 Budo MLD, Saupe R. Modos de cuidar em comunidades rurais: a cultura permeando o cuidado de enfermagem. Texto Contexto Enferm.2005 Abr-Jun;14(2):177-85.

18 Le Breton D. Que sais-je?: la sociologie du risque. Paris: Presses Universitaires de France; 1995. 